\title{
UNIVERSAL SOUND RECORDER USING ARM 9
}

\author{
Priyanka R. Pandharpurkar ${ }^{1}$, M.T.Kolte ${ }^{2}$ \\ ${ }^{1}$ P.G.Student, Vlsi \& embedded system, M.I.T. College Of Engineering, Pune. \\ ${ }^{2}$ Prof. Dean \& PG Co-ordinator, Electronics \& Telecommunication, M.I.T. College Of Engineering, Pune.
}

\begin{abstract}
In market there are many sound recorders present now days designed for recording of sound in digital format. Digital sound recorders present in market are designed on different platforms. This particular sound recorder designed is designed on ARM 9 base. This sound recorder records sound in .wav format. Along with recording sound can be stored in multiple memory devices/systems. Here, it is stored in S.D. card as well as U.S.B device connected. Using this device multiple users can have recorded audio file without having their individual sound recorders. Just by connecting their U.S.B devices to system, they can have recorded file in wav format. This system provides recorded file directly to U.S.B devices. Along with recorded file can be transferred to remote place too.
\end{abstract}

Keywords: ARM 9, S.D. card, U.S.B device, .wav format and remote place.

\section{INTRODUCTION}

Now a days, for different conferences, meetings even during lectures \& practicals, people are tend to use sound recorders. It is most convenient way to have information without incurring any information loss. Previously, people were subjected to take notes manually which was quite difficult \& had chances to skip some portion. Now while attending lectures, meetings, conferences users can have their individual data at the same time without having own sound recorderss simultaneously can have that particular data.Long before sound was being recoreded, music was being recorded, first by means of written notation, then also in forms that made it possible for the music to be played automatically by a mechanical device. Basically, sound recording is recreation of sound waves such as spoken voice, instrumental music, singing or different sound effects. Sound recording can be done in two forms, analog \& digital. In decades before $90 \mathrm{~s}$ when there was no such thing like recording in digital form, analog recording was done with the help of tapes. It usually uses magnetic tapes. In magnetic tape recording, sound waves vibrate on electric diaphragram $\&$ are converted into varying electric current.

In digital recording, first the analog sound is converted into digital form by using process called as digitization, which allows it to be stored \& transmitted by variety of area. Digital recordings are considered of higher quality than analog recordings for different reasons. They have wider frequency range \& higher. The proposed system is one module which consist

1. ARM 9

2. Mini 2440

3. U.S.B ports \& S.D. card for storing purpose.

This system is different from other system because it will be having S.D. card as well as US.B. device storage used for user to have recorded audio file. In this system first sound will be recorded \& stored in systems internal memory. Then we will have to boot S.D. card \& U.S.B device. After booting, recorded audio file can be transferred to S.D. card \& U.S.B device connected.

In this way, user can have recorded file with himself in his storage device without having particular sound recorder.

\section{PREVIOUS WORK}

The first device that could record actual sounds as they passed through the air was phonoautograph, which was patented in 90s by Parisian inventor Edouard-Leon Scott Marinville. The earliest known recordings of human voice are phonautograms.

Cros is remembered as the earliest inventor of a sound recording and reproduction machine. The first practical sound recording and reproduction device was the mechanical phonograph cylinder, the invention soon spread across the globe and over the next two decades the commercial recording, distribution and sale of sound recordings became a growing new international industry, with the most popular titles selling millions of units by the early 1900s.

Ki-Man Kim , Young-Keun Choi [5] proposed a new approach for rustle noise cancellation in pen-type voice recorder .A signal subspace approach method is proposed.They achieved a saving on computational complexity using subband domain processing Hong Zhao and Hafiz Malik [3] stated Audio Recording Location Identification. As audio recording is supposed to be subjected of number of possible distortions. Majorly artificts considered here are background noise \& acoustic reverberation. Smilen Dimitrov [4] Demonstrated Arduino Duemillanove board Which contains a USB interface chip Rather than controlling the soundcard using their favorite 'media player' or 'recorder' audio software from the PC, they have given the soundcard interfaces with various audio equipments. 
Zhi Yang, Qi Zhao [6] proposed vivo neural recording in which they have studied multiple noise sources for in vivo neural recording. Seon Man Kim, Chan Jun Chun [8] proposed multichannel audio recording. In this paper, an audio recording method is given in which a near-coincident microphone array is used for a multichannel audio system. To capture spatial A coincident or near-coincident microphone recording method attempts images in a multichannel audio system depending on directional-level differences or directivities.

\section{PROPOSED SYSTEM BLOCK DIAGRAM}



Fig. 1 Proposed Block Diagram

\section{WORKING OF PROPOSED SYSTEM}

There are mainly 4 steps while working of proposed system:

1. Record sound with help of mic.

2. To record that audio file, we need voice recorder application which is produced by compiling kernel, which will produce my image leading to generate application of voice recording.

3. Later we have to boot S.D. card \& U.S.B device so that audio file can be transferred to S.D. Card as well as U.S.B device connected.

4. Store that audio file transferred to S.D. Card as well as U.S.B device connected.

Hence, recorded audio file in .wav format will be available to users without having their own sound recorders.

\section{PROBLEMS WITH PRESENT SOUND RECORDERS}

Results can be obtained in far better format than digital sound recorders now-a-days present in market. Following are some problems which occur with digital sound recorders present.

1. Microphone frequency range :

This is the frequency range that the microphone is capable of recording. The average human can hear as low as $20 \mathrm{~Hz}$ $\&$ as high as $20 \mathrm{kHz}$.

\section{Low cut filter :}

This is a frequency filter that minimizes the sounds caused by breathing, plosives, wind \& ambient humming from things like PA speakers or computer fans.

\section{Dead air removal :}

This setting automatically removes or skips silent moments in a recording. This provides an efficient way of reviewing $\&$ transcribing audio from meeting, lectures \& dictations.

\section{Storage :}

This is amount of storage for recording audio. This can be internal storage or an included storage card. The size of each audio file depends on the quality of the format, the length \& the amount of detail within the audio. On average, when using the highest quality formats, $1 \mathrm{~GB}$ of storage is approximately $5.5 \mathrm{hrs}$ of MP3 audio and 37 minutes of WAV audio.

\section{Maximum Battery life :}

This is the maximum life of the battery during continuous use. Battery life varies depending on the type of format \& settings used. This represents the longest possible battery life, which means that it's using the least data intensive format.

Different sound recorders present in market are based on different technologies. Here, Digital sound recorder designed is designed on ARM 9 base. There are number of advantages of using ARM 9 as base for sound recording. Sound recording on front end becomes extremely easy process just as after developing sound recording application, user/speaker will be able to record his/her speech \& will be able to provide it for multiple audiences without having their individual sound recorders. As sound recoders present in market are costly at money prize \& if sound recorders which are low at cost are purchased, there user have to compromise in case of sound quality, range, recording hours, etc. Even if user thought about sound recorders which are low at cost, the minimum low cost will be upto rs.6000. It means even after purchasing this sound recorders at this much cost, user have to compromise in case of quality. Along with sound recorder present in market at this much prize even user have to compromise with much more things.

Thus, this sound recorder designed using ARM 9 base will help to overcome these issues. Along with it will be proved cost efficient also.

\section{RESULTS OBTAINED}

Main objective to design this sound recorder using ARM 9 is to record sound, store it in it's internal memory. Later to transfer that sound into S.D. Card as well as U.S.B Device connected. No other sound recorder present in market has facility to record/transfer that recorded audio file into two memory devices. 


\section{Voice Recorder Application Created}



Fig. 2 : Voice Recorder application created for recording

Fig. 2 shows first stage for recording sound. The very first stage is to create audio recording application for recording user's speech.

\section{Recording File}

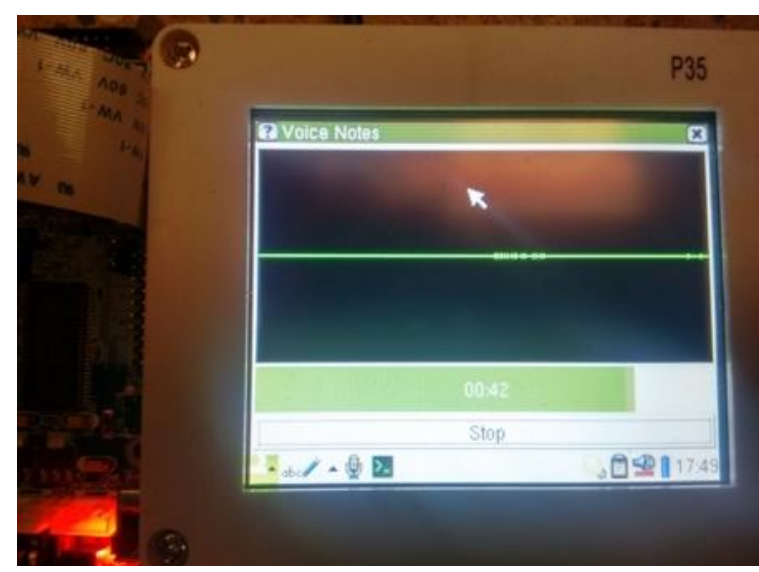

Fig. 3 : Audio file created after recording sound

Fig. 3 shows sound while being recorded. Simultaneously while speaking the speech will be recorded.

\section{Recorded file stored in .wav format}

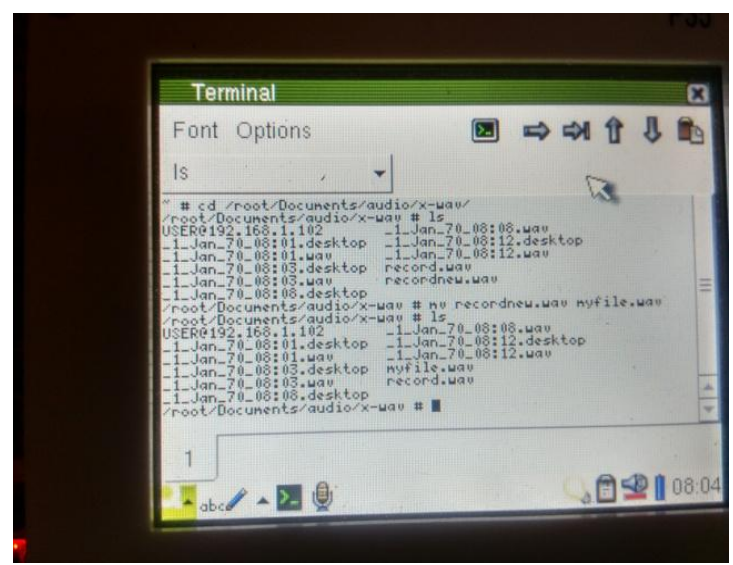

Fig. 4 : Audio file stored in .wav format

Fig. 4 shows recorded file. It is third step in which user's speech is recorded in form of .wav format in the internal memory of ARM 9.

\section{File stored in S.D. Card}

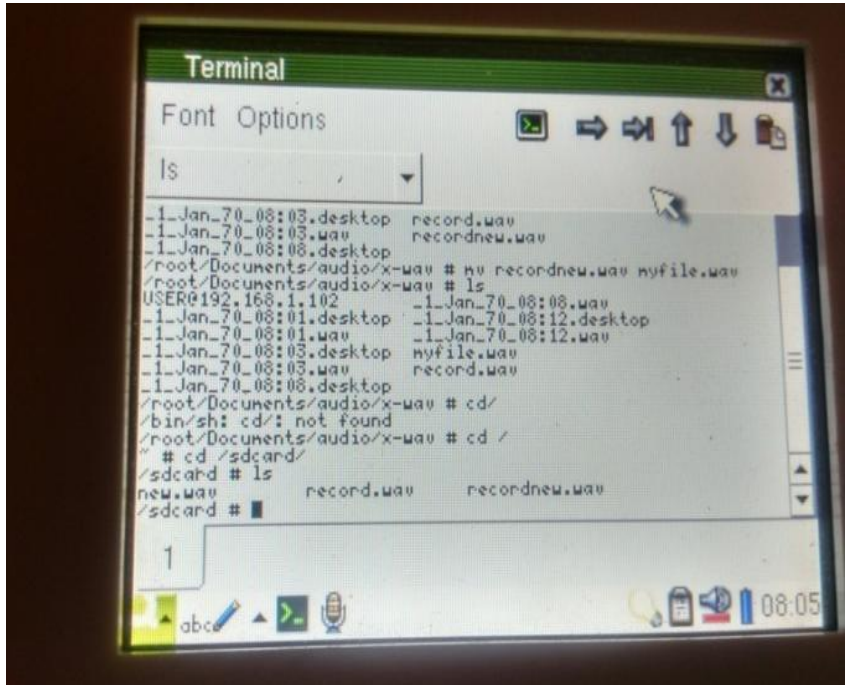

Fig. 5 : File stored in S.D. Card

Fig. 5 shows next step in proposed system. Here, the recorded audio file is transferred to one of the memory device. The first memory device used here to transfer that file is S.D. Card. It can be seen that the recorded audio file is stored/transferred into S.D. Card by name recordnew.wav.

\section{File Stored in U.S.B Device}

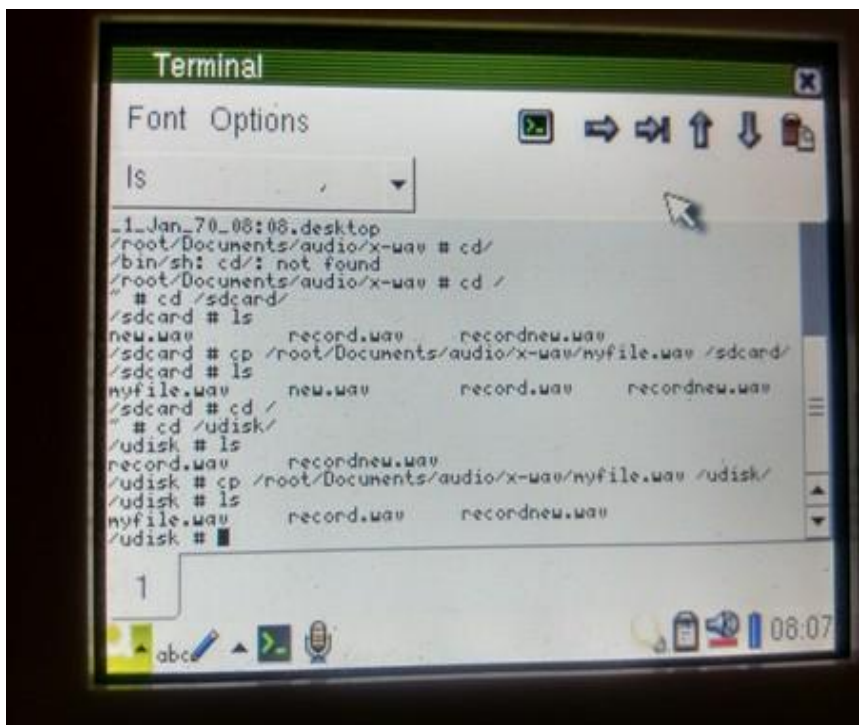

Fig. 6 : File stored in U.S.B Device

Fig. 6 shows transfer of audio file into another memory device. Another memory device considered here is U.S.B Device. It can be seen that the same audio file is transferred to U.S.B Device i.e. u disk. The audio file is named here as recordnew.wav.

Here, hence it is possible to record audio file in .wav format using base ARM 9. Along with it is possible to store that file, transfer the same audio file into S.D. Card as well as U.S.B Device. 


\section{FUTURE SCOPE}

This system can be developed for multiple U.S.B ports. There is no other system which will transfer data with multiple U.S.B ports. Here successful experimental results obtained for data transfer in multiple memory devices one of which is S.D. card \& one is U.S.B device.

\section{CONCLUSION}

Sound recording system using arm 9 processor is implemented in which sound is recorded in .wav format. Along with recording the sound, audio file is transmitted to S.D. card \& U.S.B devices. The reason for using S.D. card here is mainly for it's various advantages like low power consumption, enough capacity for all kinds of multimedia data. Data transfer to multiple users \& remotely recording of data are main advantages of proposed digital sound recorder over other sound recorders present in market.

\section{REFERENCES}

[1] Stojan Mateski, Zoran Anastasovski" Digital Sound Recorder with ARM microcontroller and SD Card" 20th Telecommunications forum TELFOR 2012.

[2] Smilen Dimitrov, Stefania Serafin "Audio Arduino - an ALSA (Advanced Linux Sound Architecture) audio driver for FTDI-based Arduinos" International Conference on New Interfaces for Musical Expression, 30 May - 1 June 2011.

[3] Hong Zhao and Hafiz Malik "Audio Recording Location Identification Using Acoustic Environment Signature"ieee transactions on information forensics and security, vol. 8, no. 11, november 2013

[4] Ki-Man Kim , Young-Keun Choi, and Kyu-Sik Park "A New Approach for Rustle Noise Canceling in Pentype Voice Recorder" IEEE Transactions on Consumer Electronics, Vol. 49, No. 4, NOVEMBER 2003.

[5] Zhi Yang1, Qi Zhao2, Edward Keefer3;4, and Wentai Liu "Noise Characterization, Modeling, and Reduction for In Vivo Neural Recording" Yiteng (Arden) Huang, Jacob Benesty, Jingdong Chen," Analysis and Comparison of Multichannel Noise Reduction Methods in a Common Framework", ieee transactions on audio, speech, and language processing, vol. 16, no. 5 , july 2008.

[6] Seon Man Kim, Chan Jun Chun, and Hong Kook Kim" Multi-Channel Audio Recording Based on Superdirective Beamforming for Portable Multimedia Recording Devices", 2014.

[7] Sen M. Kuo, Bob H. Lee and Wenshun Tian, "RealTime Digital Signal Processing," in Chichester, England, 2006.

[8] ARM Architecture Reference Manual, ARM Limited 2005. 